\title{
TINJAUAN STRUKTUR APARTEMEN PORIS 88 TANGERANG
}

\author{
Oleh : \\ Wiratna Tri Nugraha ${ }^{2}$ \\ Hanifah Sukruliah Aminudin ${ }^{1}$, \\ Jurusan Teknik Sipil, Fakultas Teknik, \\ Universitas Suryakancana Cianjur
}

\begin{abstract}
ABSTRAK
Peninjauan struktur Apartemen Poris 88 Tangerang ini mengacu pada standar peraturan-peraturan perencanaan gedung Indonesia yang berlaku seperti, Tata Cara Perhitungan Struktur Beton Untuk Bangunan Gedung (SNI 03-2847-2002), Tata Cara Perencanaan Pembebanan Untuk Rumah dan Gedung (SNI 1727-1989) dan Tata Cara Perhitungan Struktur Beton Untuk Bangunan Gedung (SNI 03-2847-2002). Beban-beban yang ditinjau untuk perencanaan mengacu pada Peraturan Pembebanan Indonesia untuk gedung 1983 dengan menggunakan Sistem Rangka Pemikul Momen Menengah (SRPMM). Perhitungan struktur menggunakan software SAP 2000 v.15. Struktur atas meliputi kontrol kekuatan pelat, balok, dan kolom. Yang meliputi gaya aksial, gaya geser dan momen. Pembebanan yang ditinjau untuk perencanaan elemen struktur adalah beban mati, beban hidup, dan beban gempa. Analisis gempa menggunakan metode analisa statik ekivalen. Gaya-gaya dalam diperoleh dari output SAP 2000 v.15. Dan dari hasil kontrol dimensioning didapatkan bahwa beberapa balok tidak aman terhadap gaya geser, yaitu portal as A3 pada lantai 2(79);5(198);7(272);9(346);11(420) dan disimpulkan bahwa struktur bangunan tersebut kurang aman.
\end{abstract}

Kata kunci: Struktur gedung, tinjauan struktur, beton bertulang, SRPMM, SAP v.15.1.0, tulangan.

\section{PENDAhUluan}

Peninjauan ulang struktur ini disebabkan karena terjadinya beberapakali pergantian konsultan dan kontraktor. Meskipun desain tidak berubah banyak, tapi untuk hasil yang lebih akurat maka struktur perlu ditinjau ulang.

Hal ini tentunya perlu dikaji ulang mulai dari perencanana arsitektur sampai pada perhitungan kekuatan struktur agar mendapatkan hasil yang lebih akurat. Tanpa menyinggung berbagai pihak yang bersangkutan.

\section{TINJAUAN PUSTAKA}

\subsection{Balok}

Pada perencanaan gedung ini memiliki 2 jenis tumpuan pada balok dan pada pelat, yaitu satu ujung menerus dan kedua ujung menerus. Balok umumnya menjadi satu kesatuan yang monolit dengan pelat.

Pelat berlaku sebagai lapis sayap tekan yaitu sebagai komponen struktur yang bekerja pada dua arah lenturan saling tegak lurus, sedangkan balok berlaku sebagai badan. Fungsi balok adalah sebagai penyalur beban dari lantai ke kolom.

Dalam menentukan ukuran penampang balok, yaitu didasarkan pada tebal minimum $\left(\mathrm{h}_{\min }\right)$ balok terhadap panjang bentang (h), maka dilakukan pendekatan berdasarkan SNI 03-2847-2002 Tabel 2.2.

Dengan L adalah bentang terpanjang, ketentuan ini berlaku untuk nilai $\mathrm{fy}=400$ $\mathrm{MPa}$, sedangkan untuk fy selain nilai tersebut maka dikalikan dengan $(0,4+$ fy/700). Untuk lebar balok (bw), syaratnya adalah $b w=h / 2$ sampai dengan $2 h / 3$.

Pelimpahan beban merata pada balokbalok struktur dilakukan dengan metode amplop. Dengan cara ini, balok-balok struktur tersebut ada yang memikul beban trapesium dan beban segitiga. Untuk memudahkan perhitungan, beban trapesium dan beban segitiga diubah menjadi beban merata ekuivalen $\left(\mathrm{q}_{\mathrm{c}}\right)$.

Rumus: 
$\varnothing$ Beban trapesium diubah menjadi beban merata ekuivalen

$$
\mathrm{q}_{\mathrm{ek}}=1 / 2 q \cdot\left(l_{x} / l_{y}^{2}\right) \cdot\left(y^{2}-1 / l_{x}^{2}\right)
$$

Beban segitiga diubah menjadi beban merata ekuivalen

$$
\mathrm{q}_{\mathrm{e}} \quad \quad l_{3} g \cdot l_{x}
$$

Dimana: $L_{x}$ dan $L_{y}$ adalah panjang bentang untuk segmen pelat.

\subsection{Pelat}

Pelat adalah elemen struktur yang mempunyai fungsi sebagai penopang langsung beban atau tumpuan beban. Dalam perencanaan gedung ini digunakan pelat dua arah.

Pelat dua arah adalah pelat beton bertulang yang mempunyai angka perbandingan antara bentang yang panjang dengan yang pendek kurang dari 2. Pada pelat dua arah, momen yang diperhitungkan dalam dua arah $\frac{\mathbf{L y}}{\mathbf{L x}}<\mathbf{2}$, Ly merupakan bentang yang lebih panjang dan Lx adalah bentang yang pendek.

Berdasarkan Pasal 11.5.3 SNI 03-28472002, dalam menentukan ukuran penampang pelat, maka diambil panel terbesar sebagai panel yang akan ditinjau. Untuk menentukan tebal pelat perlu diketahui terlebih dahulu nilai $\alpha_{\mathrm{m}}$. Dibawah ini adalah rumus menentukan $\alpha_{\mathrm{m}}$.

$$
\alpha=\frac{\mathrm{E}_{\mathrm{cb}} / \mathrm{I}_{\mathrm{b}}}{\mathrm{E}_{\mathrm{cp}} / \mathrm{I}_{\mathrm{p}}}
$$

Untuk menghitung momen inersia pelat $\left(\mathrm{I}_{\mathrm{p}}\right)$ dan momen inersia balok ( $\left.\mathrm{I}_{\mathrm{b}}\right)$ mengunakan rumus sebagai berikut :

$$
\mathrm{I}_{\mathrm{p}}=\frac{1}{12} \times b \times h^{3} \text { dan } \mathrm{I}_{\mathrm{b} 1}=\frac{1}{12} \times b \times h^{3}
$$

(b) dan (h) pada balok adalah dimensi balok, sedangkan (b) pada pelat adalah bentang terpanjang dan (h) pada pelat diambil asumsi berdasarkan $\quad$ SNI 032847-2002, yaitu :

$$
\mathrm{h}=\frac{L y}{36} \text {. }
$$

Keterangan :

$\alpha_{\mathrm{m}}$ : Nilai rata-rata $\alpha$ untuk semua balok pada tepi-tepi suatu panel

$\alpha$ : Rasio kekuatan lentur penampang balok terhadap kekakuan lentur pelat

$\mathrm{E}_{\mathrm{cb}}$ : Modulus elastisitas balok

$\mathrm{I}_{\mathrm{b}}:$ Momen inersia balok beton
$\mathrm{E}_{\mathrm{cp}}$ : Modulus elastisitas pelat beton

$\mathrm{I}_{\mathrm{p}}$ : Momen inersia pelat

hf : Tebal pelat

b : Panjang balok atau panjang pelat

h : Lebar balok atau lebar pelat

Fy : Kuat leleh yang di syaratkan untuk tulangan non prategang

$\beta$ : Rasio bentang bersih pelat dalam arah memanjang dan arah memendek

Lx : Bentang $x$

Ly : Bentang y

Persyaratan untuk tebal pelat adalah sebagai berikut :

- Jika $\alpha_{\mathrm{m}}<0,2$, maka $\mathrm{h} \geq 120 \mathrm{~mm}$, untuk pelat tanpa penebalan

$\mathrm{h} \geq 100 \mathrm{~mm}$, untuk pelat dengan penebalan

- Jika $0,2 \leq \alpha_{\mathrm{m}} \leq 2$, maka $\mathrm{h}=$ $\frac{\operatorname{Ln}\left(0,8+\frac{\mathrm{fy}}{1500}\right)}{36+5 \beta(\alpha \mathrm{m}-0,2)}$ dan $\geq 120 \mathrm{~mm}$

- Jika $\alpha_{\mathrm{m}}>2$, maka $\mathrm{h}=\frac{\operatorname{Ln}\left(0,8-\frac{\mathrm{fy}}{1500}\right)}{36-9 \beta} \mathrm{dan} \geq$ $90 \mathrm{~mm}$

\subsection{Kolom}

Kolom adalah komponen struktur vertikal yang meneruskan beban dari balok atau pelat sehingga sampai pada pondasi. Keruntuhan pada suatu kolom merupakan penyebab utama keruntuhan total struktur gedung itu sendiri. Oleh karena itu dalam perencanaan gedung ini, kolom direncanakan lebih kuat daripada balok yang lebih dikenal dengan kolom kuat balok lemah.

Dalam perencanaan gedung ini, direncanakan kolom bujur sangkar dengan $\mathrm{b}=\mathrm{h}$. Berdasarkan SNI 03-2847-2002 Pasal 10.10.2, lebar pelat efektif sebagai bagian dari balok-T tidak boleh melebihi $1 / 4$ bentang balok ( $b f \leq 1 / 4 \mathrm{~L}$ ). Sedangkan lebar efektif sayap dari masing-masing badan balok tidak boleh melebihi ( $8 \mathrm{hf}$ ) dan tidak boleh melebihi (1/2 Ln) antara balok-balok yang bersebelahan.

\section{METODOLOGI}

Tahapan perhitungan struktur:

1) Menghitung pembebanan mati terhadap kolom, balok, dan pelat.

2) Menghitung pembebanan hidup pada kolom, balok dan pelat.

3) Menghitung beban gempa. 
4) Menghitung gaya aksial, gaya geser dan momen menggunakan SAP 2000 v.15.

5) Menghitung dimensi kolom, balok dan pelat sebagai perhitungan akhir.

\section{HASIL DAN PEMBAHASAN}

\subsection{Hasil Perhitungan Pelat}

Menentukan koefisien momen pada pelat

Koefisien untuk plat 1 arah dan plat 2 arah adalah berbeda. Koefisien momen untuk plat 2 arah ditentukan berdasarkan tabel Momen di dalam plat persegi yang menumpu pada keempat tepinya akibat beban terbagi rata. Untuk tabelnya diambil dari Afret Nobel, ST (disertakan di lampiran)

Pada kasus ini saya mengambil plat pada bentang tengah artinya menerus / terjepit elastis di keempat sisinya. Dengan nilai $\mathrm{K}=$ 1.5 dan dicocokkan ke tabel maka diperoleh nilai $\mathrm{X}=50,38,38$.

- Momen beban Mati / Dead load $\circ \mathrm{Mtx}=0,001 \mathrm{qlx}^{\wedge} 2 . \mathrm{X}=3,63 \mathrm{kNm}$ $\circ \mathrm{Mly}=\mathrm{Mty}=0,001 \mathrm{qlx}^{\wedge} 2 \cdot \mathrm{X}=2,76 \mathrm{kNm}$

- Momen beban hidup / Live load

$\circ \mathrm{Mtx}=0,001 \mathrm{qlx}^{\wedge} 2 . \mathrm{X}=2,53 \mathrm{kNm}$

$\circ \mathrm{Mly}=\mathrm{Mty}=0,001 \mathrm{qlx}^{\wedge} 2 . \mathrm{X}=1,93 \mathrm{kNm}$

- $\mathrm{Mu}=$ Momen perlu

○ 1,2 MDL + 1,6 MLL (kombinasi pembebanan untuk plat lantai)

o Mutx $=8,41 \mathrm{kNm}$

$\circ$ Muly $=$ Mulx $=6,4 \mathrm{kNm}$

Menentukan luas tulangan

- As perlu (luas tulangan yang dibutuhkan berdasarkan momen yang terjadi)

$\circ$ Mutx $=($ Mu.1000000 $) /(0,8$.fy.d $)=438$ $\mathrm{mm}^{2}$

$\circ$ Muly $=$ Mulx = (Mu.1000000) $/\left(0,8\right.$. fy.d) $=333 \mathrm{~mm}^{2}$

- As minimum (luas tulangan minimum sesuai persyaratan $\mathrm{SNI}$ )

$\circ 0.0018$. b.d $=0,0018 \cdot 1000 \cdot 100=180$ $\mathrm{mm}^{2}$

- As maksimum (luas tulangan maksimum sesuai persyaratan $\mathrm{SNI}$ )

o Diperoleh $438 \mathrm{~mm}^{2}$

- Jika digunakan tulangan diameter $10 \mathrm{~mm}$ $\left(\mathrm{As}^{\prime}=79 \mathrm{~mm}^{2}\right)$, maka diperoleh:

o Tulangan searah $\mathrm{x}$ (bentang pendek) = $1000 /($ As $/$ As' $)=1000 /(438 / 79)$

$=\mathrm{D} 10-180 \mathrm{~mm}$

o Tulangan searah y (bentang panjang) $=\mathrm{D} 10-240 \mathrm{~mm}$

\subsection{Hasil Perhitungan Balok}

\begin{tabular}{|c|c|c|c|}
\hline \multicolumn{4}{|c|}{ Balok As A3 } \\
\hline \multirow{2}{*}{ Lantai } & \multirow{2}{*}{ Balok } & \multicolumn{2}{|c|}{ Aksial } \\
\cline { 3 - 4 } & & $\phi \mathrm{Pn}(\mathrm{kN})$ & $\mathrm{Pu}(\mathrm{kN})$ \\
\hline 1 & 36 & 3044,56 & 39,86 \\
\hline 2 & 79 & 3044,56 & 293,29 \\
\hline 3 & 122 & 3044,56 & 40,08 \\
\hline 4 & 161 & 3044,56 & 234,4 \\
\hline 5 & 198 & 3044,56 & 22,65 \\
\hline 6 & 235 & 3044,56 & 46,29 \\
\hline 7 & 272 & 3044,56 & 56,02 \\
\hline 8 & 309 & 3044,56 & 63,55 \\
\hline 9 & 346 & 3044,56 & 75,68 \\
\hline 10 & 383 & 3044,56 & 78,54 \\
\hline 11 & 420 & 3044,56 & 86,77 \\
\hline 12 & 457 & 3044,56 & 106,39 \\
\hline 13 & 494 & 3044,56 & 101,02 \\
\hline 14 & 531 & 3044,56 & 111,85 \\
\hline 15 & 568 & 3044,56 & 113,25 \\
\hline 16 & 605 & 3044,56 & 227,25 \\
\hline
\end{tabular}

\begin{tabular}{|c|c|c|c|}
\hline \multicolumn{4}{|c|}{ Balok As A3 } \\
\hline \multicolumn{2}{|c|}{ Geser } & \multicolumn{2}{c|}{ Momen } \\
\hline$\phi \mathrm{Vn}$ & $\mathrm{Vu}$ & $\phi \mathrm{Mn}$ & $\mathrm{Mu}$ \\
& & & \\
$(\mathrm{kN})$ & $(\mathrm{kN})$ & $(\mathrm{kNm})$ & $(\mathrm{kNm})$ \\
\hline 259,94 & 148,01 & 10167,16 & 180,70 \\
\hline 259,94 & 282,96 & 10167,16 & 491 \\
\hline 259,94 & 155,16 & 10167,16 & 163,41 \\
\hline 259,94 & 179,32 & 10167,16 & 176,06 \\
\hline 259,94 & 299,83 & 10167,16 & 557,25 \\
\hline 259,94 & 189,02 & 10167,16 & 174,34 \\
\hline 259,94 & 297,04 & 10167,16 & 549,08 \\
\hline 259,94 & 179,51 & 10167,16 & 174,58 \\
\hline 259,94 & 284,05 & 10167,16 & 509,79 \\
\hline 259,94 & 162,36 & 10167,16 & 175,16 \\
\hline 259,94 & 264,03 & 10167,16 & 449,30 \\
\hline 259,94 & 142,09 & 10167,16 & 175,73 \\
\hline 259,94 & 239,84 & 10167,16 & 375,74 \\
\hline 259,94 & 115,11 & 10167,16 & 176,63 \\
\hline 259,94 & 213,63 & 10167,16 & 297,53 \\
\hline 259,94 & 64,06 & 10167,16 & 122,00 \\
\hline
\end{tabular}

\begin{tabular}{|c|c|c|c|}
\hline \multicolumn{4}{|c|}{ Balok As AJ } \\
\hline \multirow{2}{*}{ Lantai } & \multirow{2}{*}{ Balok } & \multicolumn{2}{|c|}{ Aksial } \\
\cline { 3 - 4 } & & $\phi \operatorname{Pn}(\mathrm{kN})$ & $\mathrm{Pu}(\mathrm{kN})$ \\
\hline 1 & 10 & 2468,94 & 38,78 \\
\hline
\end{tabular}




\begin{tabular}{|c|c|c|c|}
\hline 2 & 20 & 2468,94 & 39,92 \\
\hline 3 & 31 & 2468,94 & 111,34 \\
\hline 4 & 41 & 2468,94 & 63,28 \\
\hline 5 & 50 & 2468,94 & 7,86 \\
\hline 6 & 59 & 2468,94 & 10,37 \\
\hline 7 & 68 & 2468,94 & 9,29 \\
\hline 8 & 77 & 2468,94 & 5,92 \\
\hline 9 & 86 & 2468,94 & 1,87 \\
\hline 10 & 95 & 2468,94 & 6,81 \\
\hline 11 & 104 & 2468,94 & 8,85 \\
\hline 12 & 113 & 2468,94 & 1,71 \\
\hline 13 & 122 & 2468,94 & 9,76 \\
\hline 14 & 131 & 2468,94 & 5,90 \\
\hline 15 & 140 & 2468,94 & 10,10 \\
\hline 16 & 149 & 2468,94 & 10,92 \\
\hline
\end{tabular}

\begin{tabular}{|c|c|c|c|}
\hline 11 & 400 & 5158,17 & 3012,93 \\
\hline 12 & 437 & 5158,17 & 2469,33 \\
\hline 13 & 474 & 3649,07 & 1931,56 \\
\hline 14 & 511 & 3649,07 & 1393,01 \\
\hline 15 & 548 & 3649,07 & 855,07 \\
\hline 16 & 585 & 3649,07 & 318,04 \\
\hline
\end{tabular}

\begin{tabular}{|c|c|c|c|}
\hline \multicolumn{4}{|c|}{ Balok As AJ } \\
\hline \multicolumn{2}{|c|}{ Geser } & \multicolumn{2}{c|}{ Momen } \\
\hline $\begin{array}{c}\phi V \mathrm{Vn} \\
(\mathrm{kN})\end{array}$ & $\begin{array}{c}\mathrm{Vu} \\
(\mathrm{kN})\end{array}$ & $\begin{array}{c}\phi \mathrm{Mn} \\
(\mathrm{kNm})\end{array}$ & $\begin{array}{c}\mathrm{Mu} \\
(\mathrm{kNm})\end{array}$ \\
\hline 144,45 & 29,67 & 1373,77 & 39,22 \\
\hline 144,45 & 29,91 & 1373,77 & 43,66 \\
\hline 144,45 & 146,82 & 1373,77 & 369,61 \\
\hline 144,45 & 3,58 & 1373,77 & 95,22 \\
\hline 144,45 & 14,21 & 1373,77 & 116,19 \\
\hline 144,45 & 17,44 & 1373,77 & 121,50 \\
\hline 144,45 & 18,23 & 1373,77 & 121,80 \\
\hline 144,45 & 14,67 & 1373,77 & 115,43 \\
\hline 144,45 & 10,29 & 1373,77 & 106,65 \\
\hline 144,45 & 3,47 & 1373,77 & 93,15 \\
\hline 144,45 & 4,65 & 1373,77 & 78,34 \\
\hline 144,45 & 12,09 & 1373,77 & 63,32 \\
\hline 144,45 & 22,64 & 1373,77 & 42,01 \\
\hline 144,45 & 34,05 & 1373,77 & 21,06 \\
\hline 144,45 & 45,43 & 1373,77 & 0,28 \\
\hline 144,45 & 16,60 & 1373,77 & 2,42 \\
\hline \multicolumn{4}{|c|}{} \\
\hline
\end{tabular}

\begin{tabular}{|c|c|c|c|}
\hline \multicolumn{4}{|c|}{ Kolom As A3 } \\
\hline \multicolumn{2}{|c|}{ Geser } & \multicolumn{2}{c|}{ Momen } \\
\hline $\begin{array}{c}\phi \mathrm{Vn} \\
(\mathrm{kN})\end{array}$ & $\begin{array}{c}\mathrm{Vu} \\
(\mathrm{kN})\end{array}$ & $\begin{array}{c}\phi \mathrm{Mn} \\
(\mathrm{kNm})\end{array}$ & $\begin{array}{c}\mathrm{Mu} \\
(\mathrm{kNm})\end{array}$ \\
\hline 2037,7 & 241,57 & 1991,67 & 1079,40 \\
\hline 2037,7 & 251,28 & 1991,67 & 622,85 \\
\hline 2037,7 & 132,39 & 1991,67 & 265,10 \\
\hline 1762,26 & 139,63 & 1991,67 & 328,61 \\
\hline 1762,26 & 250,28 & 1991,67 & 503,51 \\
\hline 1762,26 & 234,56 & 1991,67 & 387,39 \\
\hline 1220,34 & 219,97 & 1991,67 & 334,22 \\
\hline 1220,34 & 211,69 & 1991,67 & 311,42 \\
\hline 1220,34 & 200,16 & 1991,67 & 286,28 \\
\hline 956 & 181,44 & 1991,67 & 258,61 \\
\hline 956 & 165,30 & 1991,67 & 233,50 \\
\hline 956 & 147,95 & 1991,67 & 203,90 \\
\hline 651,40 & 120,04 & 1991,67 & 168,09 \\
\hline 651,40 & 98,96 & 1991,67 & 136,41 \\
\hline 651,40 & 72,17 & 1991,67 & 95,12 \\
\hline 651,40 & 62,63 & 1991,67 & 64,35 \\
\hline
\end{tabular}

\subsection{Hasil Perhitungan Kolom}

\begin{tabular}{|c|c|c|c|}
\hline \multicolumn{4}{|c|}{ Kolom As A3 } \\
\hline \multirow{2}{*}{ Lantai } & \multirow{2}{*}{ Kolom } & \multicolumn{2}{|c|}{ Aksial } \\
\cline { 3 - 4 } & & $\phi \mathrm{Pn}(\mathrm{kN})$ & $\mathrm{Pu}(\mathrm{kN})$ \\
\hline 1 & 12 & 10625,27 & 8566,74 \\
\hline 2 & 56 & 10625,27 & 8048,30 \\
\hline 3 & 99 & 10625,27 & 7459,58 \\
\hline 4 & 141 & 9983,59 & 6898,73 \\
\hline 5 & 178 & 9983,59 & 6328,41 \\
\hline 6 & 215 & 9983,59 & 5760,74 \\
\hline 7 & 252 & 5847,78 & 5206,49 \\
\hline 8 & 289 & 5847,78 & 4654,09 \\
\hline 9 & 326 & 5847,78 & 4103,85 \\
\hline 10 & 363 & 5158,17 & 3557,97 \\
\hline
\end{tabular}

\begin{tabular}{|c|c|c|c|}
\hline \multicolumn{4}{|c|}{ Kolom As AJ } \\
\hline \multirow{2}{*}{ Lantai } & \multirow{2}{*}{ Kolom } & \multicolumn{2}{|c|}{ Aksial } \\
\cline { 3 - 4 } & & $\phi P n(\mathrm{kN})$ & $\mathrm{Pu}(\mathrm{kN})$ \\
\hline 1 & 3 & 10625,27 & 5601,44 \\
\hline 2 & 13 & 10625,27 & 5236,83 \\
\hline 3 & 23 & 10625,27 & 4828,38 \\
\hline 4 & 35 & 9983,59 & 4378,98 \\
\hline 5 & 44 & 9983,59 & 3968,31 \\
\hline 6 & 53 & 9983,59 & 3542,42 \\
\hline 7 & 62 & 5847,78 & 3129,32 \\
\hline 8 & 71 & 5847,78 & 2728,52 \\
\hline 9 & 80 & 5847,78 & 2342,81 \\
\hline 10 & 89 & 5158,17 & 1975,21 \\
\hline 11 & 98 & 5158,17 & 1624,16 \\
\hline 12 & 107 & 5158,17 & 1287,62 \\
\hline 13 & 116 & 3649,07 & 970,68 \\
\hline 14 & 125 & 3649,07 & 669,64 \\
\hline 15 & 134 & 3649,07 & 383,25 \\
\hline 16 & 143 & 3649,07 & 114,31 \\
\hline
\end{tabular}




\begin{tabular}{|c|c|c|c|}
\hline \multicolumn{4}{|c|}{ Kolom As AJ } \\
\hline \multicolumn{2}{|c|}{ Geser } & \multicolumn{2}{c|}{ Momen } \\
\hline $\begin{array}{c}\phi V \mathrm{Vn} \\
(\mathrm{kN})\end{array}$ & $\begin{array}{c}\mathrm{Vu} \\
(\mathrm{kN})\end{array}$ & $\begin{array}{c}\phi \mathrm{Mn} \\
(\mathrm{kNm})\end{array}$ & $\begin{array}{c}\mathrm{Mu} \\
(\mathrm{kNm})\end{array}$ \\
\hline 1692,88 & 137,57 & 1991,67 & 644,78 \\
\hline 1692,88 & 119,99 & 1991,67 & 246,68 \\
\hline 1692,88 & 106,49 & 1991,67 & 168,86 \\
\hline 1469,62 & 134,37 & 1991,67 & 446,86 \\
\hline 1469,62 & 169,61 & 1991,67 & 390,83 \\
\hline 1469,62 & 165,85 & 1991,67 & 303,51 \\
\hline 998,72 & 148,84 & 1991,67 & 242,25 \\
\hline 998,72 & 139,37 & 1991,67 & 216,83 \\
\hline 998,72 & 125,21 & 1991,67 & 188,36 \\
\hline 788,02 & 110,63 & 1991,67 & 164,16 \\
\hline 788,02 & 93,85 & 1991,67 & 134,29 \\
\hline 788,02 & 74,86 & 1991,67 & 104,78 \\
\hline 550,15 & 59,16 & 1991,67 & 83,95 \\
\hline 550,15 & 37,43 & 1991,67 & 47,32 \\
\hline 550,15 & 16,25 & 1991,67 & 13,56 \\
\hline 550,15 & 6,20 & 1991,67 & 20,37 \\
\hline
\end{tabular}

\section{KESIMPULAN DAN SARAN}

\subsection{Kesimpulan}

Berdasarkan analisis data dan analisis struktur yang dilakukan oleh penyusun secara terurai di bab-bab sebelumnya mulai dari analisis gambar kerja sampai analisis perhitungan pembebanan serta analisis struktur kontrol dimensioning, maka dapat ditarik kesimpulan sebagai berikut:

1. Dalam perencanaan bangunan, arsitektur dapat berpengaruh terhadap struktur bangunan sendiri.

2. Analisis struktur dilakukan dengan dua dimensi, dan hanya dilkukan pada 2 portal terekstrim baik arah X dan arah Y (portal AS A3 untuk arah X dan portal AS AJ utuk arah Y)

3. Dari hasil kontrol dimensioning untuk pelat lantai yang dilakukan pada bentang terekstrim (4500x6000 $\mathrm{mm})$ tidak semuanya dinyatakan aman.

4. Hasil analisis yang menunjukan bahwa adanya bentang yang tidak aman. Bentang yang tidak aman ini agar menjadi aman perlu diganti, bisa dari dimensi atau penulangannya.

5. Hasil semua elemen struktur dinyatakan aman.

\subsection{Saran}

Berdasarkan hasil dari pengerjaan tugas akhir ini penulis memiliki beberapa saran untuk penulisan karya tulis berikutnya supaya didapatkan hasil penulisan tugas akhir yang lebih baik.

Untuk lebih tepatnya perhitungan stuktur analisa konstruksi ini masih perlu ditinjau dengan perhitungan asli dari perencanaan konsultan, namun narena keterbatasan bahan dan materi data yang didapat dari pihak yang bersangkutan, penulisan tugas akhir ini tidak sampai ke perbandingan dengan perhitungan asli konsultan

Penulisan ini menggunakan metode Standar Perencanaan Ketahanan Gempa Untuk Struktur Bangunan Gedung (SNI1726-2002), Tata Cara Perencanaan Pembebanan Untuk Rumah dan Gedung (SNI 1727-1989) dan Tata Cara Perhitungan Struktur Beton Untuk Bangunan Gedung (SNI 03-2847-2002). Sehingga tugas akhir ini tidak menjamin kedepannya untuk dijadikan pedoman, saran dari penulis adalah untuk selalu menggunakan metode yang terbaru yang telah ditetapkan pemerintah, sehingga tugas akhir ini dijadikan perbandingan dan referensi saja.

\section{DAFTAR PUSTAKA}

Asroni, A. 2010. Balok dan Pelat Beton Bertulang. Graha Ilmu: Yogyakarta.

Anonim, 1998. Peraturan Pembebanan Indonesia Untuk Bangunan Gedung. Badan Standarisasi Nasional.

Anonim, 2002. Tata Cara Perhitungan Struktur Beton Untuk Bangunan Gedung (SNI 03-2847-2002). Badan Standarisasi Nasional.

Antono, Achmad. 1995. Bahan Konstruksi Teknik Sipil II. Jakarta: Diktat TBK

Budiadi, Andri. 2008. Desain Praktis Beton Prategang. Andi. Yogyakarta.

Imran, Iswandi. 2010. Perencanaan Struktur Gedung Beton Bertulang Tahan Gempa, Penerbit ITB: Bandung.

Irpan. 2016. ANALISIS KEKUATAN STRUKTUR ALIH FUNGSI GEDUNG (Studi Kasus : Rumah Sakit RSIA Cianjur Menjadi Hotel Zodiak). Universitas Suryakancana: Cianjur

Nasution, Amrinsyah. 2009. Analisis dan Desain Struktur Beton Bertulang. ITB: Bandung. 
Pamungkas, Anugrah \& Erny. 2009. Gedung Beton Bertulang Tahan Gempa. Surabaya: ITS Press.

SNI 03-1726-2002. Tata Cara Perencanaan Ketahanan Gempa Untuk Bangunan Gedung. Badan Standardisasi Nasional

Bangunan Gedung. Badan Standardisasi Nasional

SNI 1727-1989. Tata Cara Perencanaan Pembebanan untuk Rumah dan Gedung. Badan Standardisasi Nasional Todd. 1984. Teori dan Analisis Struktur. Jakarta: Erlangga

Valdi. 2012. Evaluasi Perencanaan Struktur Pada Gedung Kantor Dinas Pu

Binamarga Kabupaten Cianjur Tahap 1. Universitas Suryakancana: Cianjur

Schueller, Wolfgang. 1989. Struktur Bangunan Bertingkat Tinggi. Bandung: PT. Eresco. Bangunan Gedung. Departemen Pekerjaan Umum 